\title{
Screening of Glypican- 3 Expression in Human Normal versus Benign and Malignant Tissues: A Comparative Study Glypican- 3 expression in cancers
}

\author{
Yousef Al-saraireh $^{1 *}$, Futoon Alrawashdeh², Jehad Al-shuneigat ${ }^{3}$, \\ Mohammed Alsbou ${ }^{4}$, Nedal Alnawaiseh ${ }^{5}$, Hani Al-shagahin ${ }^{6}$ and Ahmed Youssef ${ }^{7}$ \\ ${ }^{1}$ Department of Pharmacology, Faculty of Medicine, Mutah University, Al-karak, Jordan. \\ ${ }^{2}$ Department of Anatomy and Histology, Faculty of Medicine, Mutah University, Al-karak, Jordan. \\ ${ }^{3}$ Department of Biochemistry and Molecular Biology, Faculty of Medicine, Mutah University, Al-karak, Jordan. \\ ${ }^{4}$ Department of Pharmacology, Faculty of Medicine, Mutah University, Al-karak, Jordan. \\ ${ }^{5}$ Department of Public Health, Faculty of Medicine, Mutah University, Al-karak, Jordan. \\ ${ }^{6}$ Department of Special Surgery, Faculty of Medicine, Mutah University, Al-karak, Jordan. \\ ${ }^{7}$ Department of Pharmacology, Faculty of Pharmacy, Mutah University, Al-karak, Jordan
}

http://dx.doi.org/10.13005/bbra/2085

(Received: 10 April 2016; accepted: 01 June 2016)

\begin{abstract}
Glypican-3 is a heparan sulfate proteoglycans (HSPGs) expressed at plasma membrane surface. Several studies demonstrated the re-expression of glypican-3 during the malignant transformation. Glypican-3 expression in hepatocellular carcinoma was suggested to be a diagnostic marker for differential diagnosis of hepatic nodules. The aim of the study is to evaluate the diagnostic value of glypican-3 as tumor marker not only in liver tumors but also in tumors of the other organs. A total of 95 surgically excised human tissues were subjected to immunohistochemical staining using a monoclonal antibody specific for glypican-3. These human tissues cover most of the common normal, benign, malignant and metastatic tumors originated from 27 anatomic sites. The immunohistochemical results revealed that glypican-3 was expressed in $17.4 \%$ of the normal tissues studied including stomach, small intestine, kidney (Normal cortex), and pancreas, while, the expression for glypican-3 was positive in $41.8 \%$ of the benign and malignant tumors. The most frequent expressing tumor was hepatocellular carcinoma. Moreover, for the first time, several tumor entities showed glypican-3 expression including malignant meningioma, Hodgkin's lymphoma, B-non Hodgkin's lymphoma,T-non Hodgkin's lymphoma.
\end{abstract}

Key words: Cancer, Glypican-3, Hepatocellular carcinoma, Immunohistochemistry, Proteoglycan.

HSPGs are proteins widely expressed in mammals constituting the cell surfaces and the extracellular matrix (ECM) ${ }^{1}$. One of the interesting families of HSPGs is glypicans which are bound to external surface of plasma membrane by a glycosylphosphatidylinositol anchor. In mammals' genome, six family members of glypicans have been

\footnotetext{
* To whom all correspondence should be addressed. E-mail: Yousef.sar@mutah.edu.jo
}

identified namely glypican- 1 to glypican- $6^{2-5}$. Their expression levels predominate during development showing variability in the stage and tissue specific manner. Through their two negatively charged chains of heparan sulfate glycan, they act as coreceptors for fibroblast growth factors, insulin-like growth factors and Wnts. These interactions are believed to regulate critically cell signaling events during developmental morphogenesis and adult physiology ${ }^{2,4,6}$.

In the last decade, the interest for 
glypicans study has gained an attention by the discovery that glypican-3 act as onco-fetal protein in some tumors. The expression of the gene encoding for glypican-3 mRNA and protein is normally suppressed in some adult tissues and abnormally re-expressed during malignant transformation ${ }^{2,7}$. Based on the tissue type, glypican-3 tends to show different pattern of expression during tumor progression, it is highly expressed in hepatocellular carcinoma, embryonic tumors, and colon cancer compared with the corresponding normal tissue ${ }^{8-10}$, while, the expression was absent in mesotheliomas, ovarian and mammary cancers ${ }^{11-14}$. Therefore, the role of glypican-3 in tumor progression seems to be controversial behaving a tumor suppressor protein in breast and ovary cancers and an oncogenic protein in development of liver, colon and embryonic tumors.

Recently, high glypican-3 expression in hepatocellular carcinoma was applied to differentiate between livers with hepatocellular carcinoma from healthy livers and benign liver lesions ones ${ }^{10,15}$. Moreover, serum levels of glypican-3 were elevated in patients with hepatocellular carcinoma but not in the other liver diseases ${ }^{16}$. Therefore, glypican-3 was suggested to be a potential serological and histological biomarker for the diagnosis of hepatocellular carcinoma. In this study, the aim was to investigate the glypican-3 expression in different human tissues including most of the common benign, malignant and metastatic tumors originated from 27 anatomic sites, with the focus on evaluating of specificity of glypican-3 as a potential diagnostic tumor marker not only in liver tumors but also in tumors of the other organs.

\section{MATERIALSAND METHODS}

\section{Tissue specimens}

Ninety five tissue specimens were selected to be enrolled in the study originated from 27 anatomic sites, out of them seventy two were from 40 tumor entities and the rest were normal tissue specimens from different organs. All the samples were previously collected for other purposes form Royal Medical Services and King Abdullah University Hospital. All personal data for samples were kept anonymous. The study was ethically approved by the Ethics Committee, Faculty of Medicine, University of Mutah.

\section{Immunohistochemistry}

Four $\mu \mathrm{m}$-thick formalin-fixed and paraffinembedded (FFPE) tissue sections were deparaffinised and rehydrated by transferring them through xylene and serial dilutions of alcohol. To block endogenous peroxidase activity, the sections were treated for 5 minutes with 3\% hydrogen peroxide $\left(\mathrm{H}_{2} \mathrm{O}_{2}\right)$ (Abcam, UK). Antigen retrieval was performed by microwaving the slides at $600 \mathrm{~W}$ for 20 minutes in citrate buffer (10 mM citrate buffer, $\mathrm{pH}$ 6.0). Prior to antibody incubation, the nonspecific binding sites of the antibodies were blocked by incubating the sections for 20 minutes at room temperature with $1.5 \%$ normal goat serum. Sections were then, incubated with rabbit monoclonal anti-glypican-3 (clone:SP86) (Abcam, UK) at concentration of $(5 \mu \mathrm{g} / \mathrm{ml})$ for one hour at room temperature. Following the treatment with primary antibody, each section was incubated with goat anti-rabbit peroxidase-conjugatedsecondary antibody (Vector Laboratories Ltd, Peterborough, $\mathrm{UK})(7.5 \mu \mathrm{g} / \mathrm{ml})$ for 30 minutes at room temperature. Immunoreactivity was visualised by incubating sections with 3,3-diaminobenzidine (DAB) (Vector Laboratories Ltd, Peterborough, UK) solution for 3-5 minutes. Following the colour development, sections were then, counterstained in Harris's haematoxylin solution mounted with coverslips using DPX medium. The slides were viewed and analyzed by using a Leica DMRB microscope (Leica DMRB, Wetzlar, Germany) with the images digitally captured and processed using a Leica MPS52

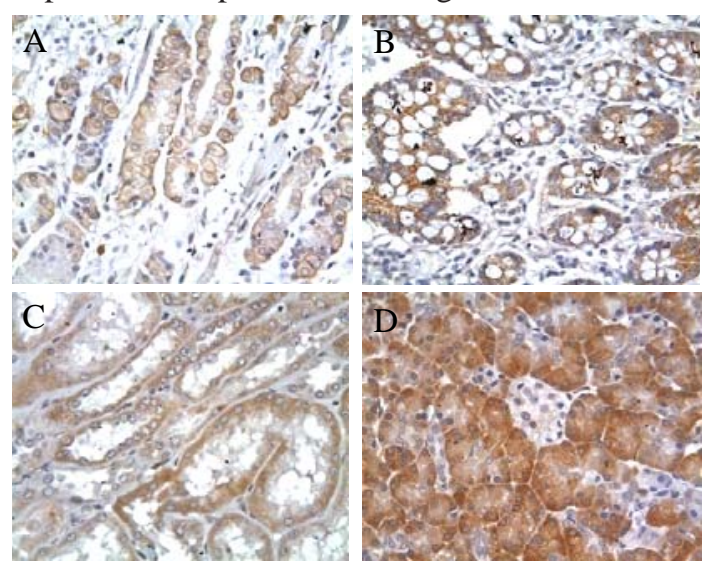

Fig. 1. Figure.1. Expression of glypican-3 in normal tissues of stomach (A), Small intestine (B), Normal cortex of kidney (C) and Pancreas (D). Magnification (X400) 
camera (Q Imaging, Germany) and the AcQuis imaging capture system (Synoptics, Cambridge, UK), respectively.

\section{Normal tissues}

A total of 23 normal tissue samples were tested for glypican-3 expression.Glypican-3 expression was positive in normal tissue of stomach, small intestine, kidney (normal cortex), and Pancreas [17.4\%] (Figure.1).Other normal tissues were negative for glypican-3 expression and these include adrenal gland, bladder, breast, colon, cerebellum, cerebra, oesophagus, liver, lymph node, rectum lung, ovary, prostate, salivary gland, testis, thyroid, skin, uterine endometrium and uterine cervix.

\section{Benign and malignant tissues}

A set of 67 benign and malignant tumor specimens related to 40 tumor entities were evaluated for glypican-3 expression, which was positive for 28 tumor samples (41.8\%) while, the
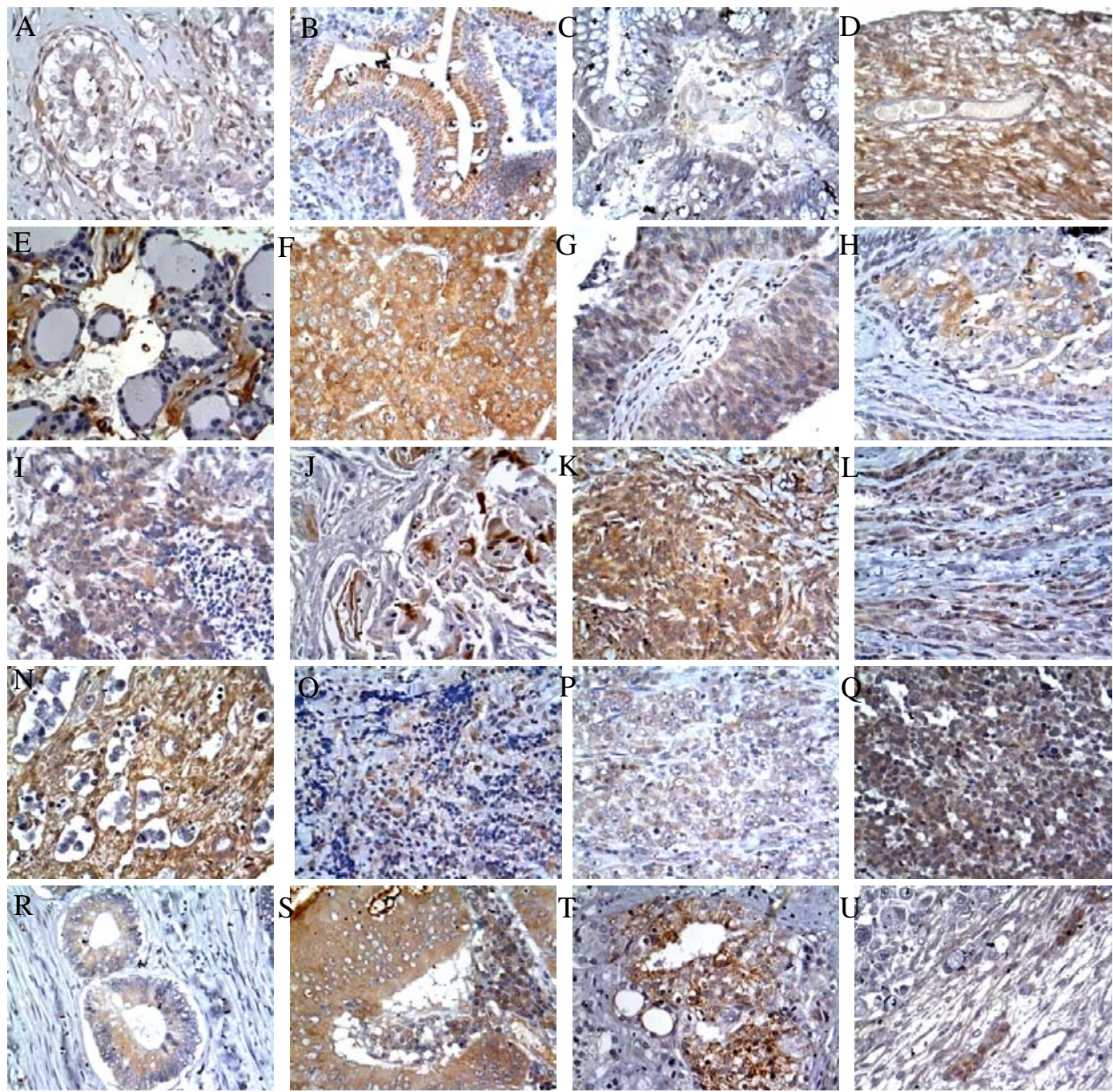

Fig. 2. Expression of glypican-3 in benign, malignant and metastatic tissues. (A-E) showing immunoreactivity of glypican-3 in adenomas of breast, small intestine, colon, ovary and thyroid respectively. Several malignant primary tumors displayed glypican-3 expression including carcinomas of liver (F), transitional cell of bladder (G), squamous cell of esophagus (H), small cell of lung (I), squamous cell of tongue (J), malignant meningioma (K), melanoma (L), seminoma $(\mathrm{N})$, hodgkin's lymphoma $(\mathrm{O})$, B-non hodgkin's lymphoma (P),T-non hodgkin's lymphoma (Q), and finally adenocarcinomas of colon (R), rectum (S), and prostate (T). Glypican-3 immunoreactivity was also demonstrated in metastatic ovarian tissues that have been originally derived from colon carcinoma (U). Magnification (X400) 
others were negative. Several types of benign tumors demonstrated glypican-3 expression (88.8\%) including adenomas of breast, small intestine, colon, ovary and thyroid. Regarding the malignant types and as expected, the most prominent tumor type that expresses glypican-3 was hepatocellular carcinoma (4/5, 80\%). Other malignant tumors also, showed glypican-3 expression including carcinomas of transitional cell of bladder, squamous cell of esophagus, small cell of lung, squamous cell of tongue, malignant meningioma, melanoma, seminoma, hodgkin's lymphoma, B-non hodgkin'slymphoma,T-non hodgkin's lymphoma, as well as adenocarcinomas of breast, colon, rectum, and prostate. (Figure 2).

\section{Metastatic tissues samples}

Here, several metastatic tissue samples were investigated for glypican-3 expression. These tumor tissues were surgically excised from metastatic sites of liver, lung, ovary and lymph nodes, which were originally derived from primary carcinomas of colon, gastric, breast and squamous cell of lymph node, respectively. The expression of glypican-3 was only positive in metastatic ovarian tissues that were originally derived from colon carcinoma (Figure 2. U).

\section{DISCUSSION}

The key rational of the current study is to address the usefulness and potential diagnostic options of glypican-3 not only in liver cancers but also in other tumor types. A confident diagnosis of tumors is really a critical step before any treatment. Therefore, the development of new tumor biomarkers that offer sensitive, cheap and specific detection of tumors is urgently needed ${ }^{17}$.

Several trials to establish an immunohistochemical detection method were made to optimize experimental conditions including the antigen retrieval method and concentration of monoclonal anti-glypican-3 antibody (clone: SP86), where different antigen retrieval treatments were used to provide better morphology.

Although, several studies were conducted on the expression of glypican-3 in human tumors, but, little researches investigated its expression in normal human adult tissues. The obtained results in the current study revealed a remarkable pattern of glypican-3 expression in the normal tissues of stomach, small intestine, kidney (normal cortex), and pancreas. In contrast, Baumhoer et al. ${ }^{1)}$ reported the expression of glypican-3 only in gastric glands, kidney tubules, and testicular germ cells but not in the small intestine and pancreas. This observation led us to question whether and how frequently glypican-3 was expressed in normal tissues.

Our study showed over-expression of glypican-3 expression in adenomas of breast, small intestine, colon, ovary and thyroid tissues versus the corresponding normal tissues. Regarding the malignant tumors, the immunohistochemical results in the present study showed that hepatocellular carcinoma was the most prominent and frequent tumor that expresses glypican-3, while, it was undetectable in the normal liver tissues. This high expression of glypican-3 was similar to previous studies which further support the potential diagnostic value of glypican-3 as a biomarker for hepatocellular carcinoma ${ }^{16,18-24}$.

As most of the reports focused on the utility of glypican-3 expression as a biomarker for hepatocellular carcinoma, other reports highlighted a broader carcinogenetic role of its expression in melanoma ${ }^{25}$, germ cell tumors ${ }^{26-28}$, and embryonic tumors ${ }^{8,9}$. Our findings are consistent with glypican3 expression in carcinomas of transitional cell of bladder, squamous cell of tongue and esophagus, small cell of lung, as well as adenocarcinomas of breast, colon, rectum, and prostate. Some of these tumors were recently reported to express glypican3 , while in malignant meningioma, Hodgkin's lymphoma, B-non Hodgkin's lymphoma,T-non Hodgkin's lymphoma, it had never been described before. So, the use of glypican-3 as a biomarker should be very limited as many tumors that can express glypican-3 may be mistaken with hepatocellular carcinoma.

\section{CONCLUSION}

Although the literature had suggested that the expression of glypican-3 is a characteristic of hepatocellular carcinoma. Our findings in the present study confirmed that glypican-3 had a limited impact as a biomarker and should be combined with other immunohistochemical markers to improve the accuracy of diagnosis of liver cancers. This came from the fact that our study 
showed glypican-3 expression in several tumor entities for the first time. This renders the use of glypican-3 as a sole biomarker for diagnosis of liver cancers and other tumor types.

\section{Conflicts of Interest}

The authors declare that there is no conflict of interests regarding the publication of this paper.

\section{REFERENCES}

1. Blackhall FH, Merry CL, Davies EJ, Jayson GC. Heparan sulfate proteoglycans and cancer. Br J Cancer. 2001; 85(8):1094-8.

2. Filmus J. Glypicans in growth control and cancer. Glycobiology. 2001; 11(3):19R-23R.

3. Filmus J, Selleck SB. Glypicans: proteoglycans with a surprise. J Clin Invest. 2001; 108(4):497501.

4. Fico A, Maina F, Dono R. Fine-tuning of cell signaling by glypicans. Cell Mol Life Sci. 68(6): 923-9.

5. Filmus J, Capurro M, Rast J. Glypicans. Genome Biol. 2008; 9(5):224.

6. Iglesias BV, Centeno G, Pascuccelli H, Ward F, Peters MG, Filmus J, Puricelli L, de Kier Joffe EB. Expression pattern of glypican-3 (GPC3) during human embryonic and fetal development. Histol Histopathol. 2008; 23(11):1333-40.

7. Filmus J, Capurro M. The role of glypican-3 in the regulation of body size and cancer. Cell Cycle. 2008; 7(18): 2787-90.

8. Chan ES, Pawel BR, Corao DA, Venneti S, Russo P, Santi M, Sullivan LM. Immunohistochemical expression of glypican-3 in pediatric tumors: an analysis of 414 cases. Pediatr Dev Pathol. 16(4): 272-7.

9. Saikali Z, Sinnett D. Expression of glypican 3 (GPC3) in embryonal tumors. Int $J$ Cancer. 2000; 89(5):418-22.

10. Zhu ZW, Friess H, Wang L, Abou-Shady M, Zimmermann A, Lander AD, Korc M, Kleeff J, Buchler MW. Enhanced glypican-3 expression differentiates the majority of hepatocellular carcinomas from benign hepatic disorders. Gut. 2001; 48(4):558-64.

11. Lin H, Huber R, Schlessinger D, Morin PJ. Frequent silencing of the GPC3 gene in ovarian cancer cell lines. Cancer Res. 1999; 59(4):80710.

12. Wang SK, Zynger DL, Hes O, Yang XJ. Discovery and diagnostic value of a novel oncofetal protein: glypican 3. Adv Anat Pathol. 21(6):450-60.
13. Murthy SS, Shen T, De Rienzo A, Lee WC, Ferriola PC, Jhanwar SC, Mossman BT, Filmus J, Testa JR. Expression of GPC3, an X-linked recessive overgrowth gene, is silenced in malignant mesothelioma. Oncogene. 2000; 19(3): 410-6.

14. Peters MG, Farias E, Colombo L, Filmus J, Puricelli L, Bal de Kier Joffe E. Inhibition of invasion and metastasis by glypican-3 in a syngeneic breast cancer model. Breast Cancer Res Treat. 2003; 80(2):221-32.

15. Wang HL, Anatelli F, Zhai QJ, Adley B, Chuang ST, Yang XJ. Glypican-3 as a useful diagnostic marker that distinguishes hepatocellular carcinoma from benign hepatocellular mass lesions. Arch Pathol Lab Med. 2008; 132(11): 1723-8.

16. Capurro M, Wanless IR, Sherman M, Deboer G, Shi W, Miyoshi E, Filmus J. Glypican-3: a novel serum and histochemical marker for hepatocellular carcinoma. Gastroenterology. 2003; 125(1):89-97.

17. Hanaoka H, Nakajima T, Sato K, Watanabe R, Phung Y, Gao W, Harada T, Kim I, Paik CH, Choyke PL, Ho M, Kobayashi H. Photoimmunotherapy of hepatocellular carcinoma-targeting Glypican-3 combined with nanosized albumin-bound paclitaxel. Nanomedicine (Lond).10(7):1139-47.

18. Baumhoer D, Tornillo L, Stadlmann S, Roncalli M, Diamantis EK, Terracciano LM. Glypican 3 expression in human nonneoplastic, preneoplastic, and neoplastic tissues: a tissue microarray analysis of 4,387 tissue samples. Am J Clin Pathol. 2008;129(6):899-906.

19. Coston WM, Loera S, Lau SK, Ishizawa S, Jiang Z, Wu CL, Yen Y, Weiss LM, Chu PG. Distinction of hepatocellular carcinoma from benign hepatic mimickers using Glypican-3 and CD34 immunohistochemistry. Am J Surg Pathol. 2008; 32(3):433-44.

20. Anatelli F, Chuang ST, Yang XJ, Wang HL. Value of glypican 3 immunostaining in the diagnosis of hepatocellular carcinoma on needle biopsy. Am J Clin Pathol. 2008; 130(2): 219-23.

21. Yan B, Wei JJ, Qian YM, Zhao XL, Zhang WW, $\mathrm{Xu}$ AM, Zhang SH. Expression and clinicopathologic significance of glypican 3 in hepatocellular carcinoma. Ann Diagn Pathol. 15(3):162-9.

22. Wang Y, Mu H, Liu T, Chen X, Shen Z. Enhanced specific antitumor immunity of dendritic cells transduced with the glypican 3 gene and cocultured with cytokine-induced killer cells against hepatocellular carcinoma cells. Mol Med Rep. 11(5): 3361-7. 
23. Yamauchi N, Watanabe A, Hishinuma M, Ohashi K, Midorikawa Y, Morishita Y, Niki T, Shibahara J, Mori M, Makuuchi M, Hippo Y, Kodama T, Iwanari H, Aburatani H, Fukayama M. The glypican 3 oncofetal protein is a promising diagnostic marker for hepatocellular carcinoma. Mod Pathol. 2005; 18(12):1591-8.

24. Wang L, Yao M, Pan LH, Qian Q, Yao DF. Glypican-3 is a biomarker and a therapeutic target of hepatocellular carcinoma. Hepatobiliary Pancreat Dis Int. ; 14(4):361-6.

25. Nakatsura T, Kageshita T, Ito S, Wakamatsu K, Monji M, Ikuta Y, Senju S, Ono T, Nishimura Y. Identification of glypican-3 as a novel tumor marker for melanoma. Clin Cancer Res. 2004; 10(19): 6612-21.

26. Stadlmann S, Gueth U, Baumhoer D, Moch H, Terracciano L, Singer G. Glypican-3 expression in primary and recurrent ovarian carcinomas. Int J Gynecol Pathol. 2007; 26(3): 341-4.

27. Zynger DL, Everton MJ, Dimov ND, Chou PM, Yang XJ. Expression of glypican 3 in ovarian and extragonadal germ cell tumors. Am J Clin Pathol. 2008;130(2):224-30.

28. Zynger DL, Dimov ND, Luan C, Teh BT, Yang XJ. Glypican 3: a novel marker in testicular germ cell tumors. Am J Surg Pathol. 2006; 30(12): 1570-5. 